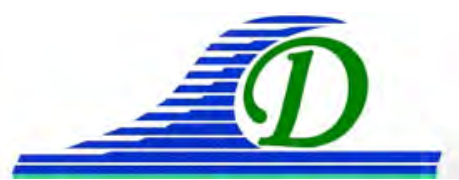

XIII ${ }^{\text {èmes }}$ Journées Nationales Génie Côtier - Génie Civil Dunkerque, 2-4 juillet 2014

DOI:10.5150/jngcgc.2014.075 C Editions Paralia CFL disponible en ligne - http://www.paralia.fr - available online

\title{
Study of a new simple form of armour unit used for coastal protection
}

\section{Iman SAFARI $^{1,4}$, Dominique MOUAZE ${ }^{1}$, François ROPERT ${ }^{2}$, Guillaume CARPENTIER ${ }^{3}$, Jean-Charles TORRES ${ }^{4}$}

1. Université de Caen, Faculté des Sciences, UMR 6143 CNRS - M2C, Esplanade de la Paix, 14032 Caen, France.iman.safari@unicaen.fr

2. CEREMA, 134 rue de Beauvais CS 6003960280 Margny-lès-Compiègne, France.

3. ESITC Caen, 1 Rue Pierre et Marie Curie, 14610 Epron, France.

4. EMCC, 7 rue Ernest Flammarion, ZAC du petit le Roy, Chevilly Larue, 94659 RUNGIS Cedex, France.

\section{Communication non présentée}

\begin{abstract}
:
Compact artificial units with protrusions (such as Accropod ${ }^{\mathrm{TM} I I}$ or Xbloc ${ }^{\circledR}$ ) are used in rubble mound breakwaters for their efficiency in extreme wave events. Recent research studies on such kind of units (Starbloc ${ }^{\circledR}$ ) have focused on fluid processes close to the armour layer related its roughness, permeability and stability. Lessons drawn for the resulting knowledge of these research works have led to design a new armour unit offering stability, controlled run-up and easy placement. In this paper, 2D hydraulic stability tests are discussed.
\end{abstract}

Keywords: Armour unit, Hydraulic Stability, Permeability, Rubble Mound Breakwater. 
Thème 4 - Ouvrages portuaires et offshore 
XIII ${ }^{\text {èmes }}$ Journées Nationales Génie Côtier - Génie Civil Dunkerque, 2-4 juillet 2014 
Thème 4 - Ouvrages portuaires et offshore 
XIII ${ }^{\text {èmes }}$ Journées Nationales Génie Côtier - Génie Civil Dunkerque, 2-4 juillet 2014 
Thème 4 - Ouvrages portuaires et offshore 
XIII ${ }^{\text {èmes }}$ Journées Nationales Génie Côtier - Génie Civil Dunkerque, 2-4 juillet 2014 
Thème 4 - Ouvrages portuaires et offshore 
XIII ${ }^{\text {èmes }}$ Journées Nationales Génie Côtier - Génie Civil Dunkerque, 2-4 juillet 2014 
Thème 4 - Ouvrages portuaires et offshore 